\title{
Study on Teaching Mode of Communication English in Business Based on Mobile Network Environment
}

\author{
Ying Cui ${ }^{\mathrm{a}}$, Xiaoli Duan ${ }^{\mathrm{b}}$ \\ Department of Environmental Economics and Information, Changsha Environment protection \\ vocational college, Changsha, China, 410004, China \\ a15399310@qq.com, ${ }^{b} 1024074301 @ q q . c o m$
}

\begin{abstract}
Business Communication is vital in Business English Major student teaching procedure, it is one of the significant and difficult points in cultivating Business English major students' professional abilities and many students have deficiency in this field. Especially in the traditional education mode, not only teachers are struggling to teach the course, but many students are also difficult to raise interest in learning. The emergence of mobile networks has brought many advantages to communication English teaching. If used properly, it can not only reduce the teaching burden for English teachers, improve teaching efficiency, but also greatly enhance students' enthusiasm for learning.
\end{abstract}

Keywords: Mobile network environment; business communication; teaching mode of business English.

\section{Introduction}

The arrival of the Internet + era and the popularization of information technology have enabled more methods and channels for curriculum teaching and teacher-student interaction. This paper first expounds the problems existing in current communication English in business teaching, and then puts forward how to effectively combine the application of current mobile network with the teaching of communication English in business, change the inefficiency of classroom teaching in the past, the lack of students' enthusiasm for learning and the superficiality of communication. The problem is then explored to take advantage of the mobile network environment to enable students to combine teaching and practice, and finally to give summary and perfect advises .

\section{Teaching Advantages in Mobile Network Environment}

Mobile network is a product of the joint development of mobile terminals and networks. It can transform the teaching process from flat to multi-dimensional, making the teaching process more diverse, allowing students to experience the two-way interaction and all-round development that is not realized in traditional teaching. For college business communication English teaching, it is necessary to mobilize students' enthusiasm for learning, enhance participation, and improve humanistic quality. Teaching can't be simply limited to "teaching" and "learning", but students should have independent choice in "listening", "speaking", "reading","practice", "self-evaluation" and "mutual evaluation", and use the mobile Internet to enrich the teaching methods of teachers. It should enable students to truly simulate and participate in business communication activities, so that students have a sense of substitution and participation. And then, under the premise of continuously completing business communication projects, greatly improve the motivation and topic of students in English communication, then the content of communication is more depth and breadth.

In addition, students can also present their ideas through the mobile network and English speech, perfect for students to express their sense of accomplishment, which greatly promotes the interest of learning.

\section{The Teaching Status of Communication English in Business}

The current teaching of communication English in business is mainly in the English audio-visual course and the oral English course. Although there are a lot of exercises, it is mainly based on daily 
communication. All the content related to business communication, students are mostly reciting, and Can not really experience the importance and variability of business communication, but in the process of reciting, because of the gap with the actual use, students become bored or tired. The main problems are:

\subsection{The Teaching Contents are Unitary and Impractical}

In current communication English in business, most textbooks are focus in business transaction procedures, no matter product promotion, inquiry, price negotiation, payment method negotiation, the contents are almost the same, there is few new change in the past years, students rarely touch these foreign trade processes in real life. Whenever the practices involving business aspects, Communicative exercises are either silent or slightly processed for the content of the text, lacking flexibility and practical application. The business communication and negotiation, which should be wonderful and tit-for-tat, becomes the coping for the teacher's classroom work. In fact the discussion in the business communication is not only to have a good level of oral expression, but also to master various scenes of business communication, and a good level of humanity, know how to cut in or change topics at the right time. teachers provide a rich and diverse experience of business communication to improve student participation, and guide students to make statements on their own initiative. This is the key to making them willing to talk and be willing to communicate or negotiate in multiple directions. Therefore, completely get rid of coping style, memorize communication, it Is the most important task of communication English in business..

\subsection{The Inefficiently Use of Network}

The mobile network not only has rich teaching resources, but also diverse mobile terminal devices make students learn more actively. There are also many ways to break through the traditional model and attract people. If you can choose these teaching methods according to the actual needs of the text content, Can achieve amazing teaching results. The use of mobile networks and their terminal devices is a very portable and novel teaching tool. In many teaching fields, the teaching advantages that cannot be underestimated have been revealed, and the teaching of many subjects has been promoted. However, due to the novelty of this method, some traditional teachers are not accustomed to making new changes to the teaching model, resulting in many courses still not effective, even teachers appear in the classroom, students secretly play mobile games below, teaching The effect is not good, both teachers and students feel that the class is tired.

\section{Construction of Communication English in Business Teaching Mode under Mobile Network Environment}

The mobile network environment and the use of mobile terminal devices bring many powerful conditions for the teaching of communication English in business. First of all, with the help of mobile networks, students can independently find a variety of content of the same theme with more variety and personal preferences, which is greatly enriched. Secondly, The teaching content is also very strong to enhance the participation of students, which is very beneficial to abundant the content of communication English in business teaching. In general, the construction of communication English in business teaching mode in the mobile network environment can start from the following two aspects:

\subsection{Re-positioning the Subject of the Classroom}

In the traditional classroom, teachers are the main body of teaching activities. They act as the host, the teacher, the game rule maker and the judge in the classroom. They are absolute authority and subject, and the students are passively receiving, joining, and answering in the whole teaching activities. The students who were born after 1990 and 2000 have strong performance and independent personality, long time to participate in such a course will be easy to get bored. However, the existence and popularity of the mobile network environment has improved this phenomenon. Teachers are no 
longer the absolute subject in classroom teaching. Students can also participate in teaching, in some certain situations, even students can play an absolute subject in experience practice. which enhanced the participation of teaching and strengthened the teaching effect.

\subsection{New Teaching Mode Promotes Students' Enthusiasm for Learning}

This study takes the 16-level cross-border e-commerce and the 17-level business English students' most common teaching unit product promotion as an example. The class size is 43 and 47 respectively. Before the start of the course, students will be divided into different groups according to their own interests through mobile network terminal equipment. Each group recommends a product that they are very interested in and a preliminary understanding of the product. The teacher analyzes and explains the contents of this module, and learns the model of product promotion and advertising. Then ask the students to give an example of the characteristics of the products they choose and the advantages compared with other similar products. The teacher commented on the student's statement and show the most famous and characteristic product promotion on the network. Then arrange the assignments, ask the students to personally design and produce a product promotion plan for the products they choose, and a simple product promotion advertisement, which can be video or audio or poster.

In the next lesson, students will be divided into small groups for presentations and speech promotion, and finally vote with mobile network terminal equipment to select the promotion plan that you think is the best or most creative, except for your own group. In the teaching of the unit, the students have a high degree of participation. The two classes are independently composed into 10 groups and 12 groups. The products they choose are from cars to jewelry, from mobile phones to Laoganma, from shoes to biscuits. The products are variety, the promotion methods and ideas are completely different. The collision of different ideas of different products makes students excited and happy, and they are elated for their affirmation by their classmates. Even if they are not the best, They will secretly encourage themselves to work harder for their own creativity in next practice. At the end of the show, students grouped out their feelings and experiences in the design. A group of students who presented the red wine promotion video considered to be the best and resonated with the students. They explained the Original intention and inspiration and said They liked the course schedule for the event. The filming took 2.5 hours. The location they chose was the college library. The total cost was about $70 ¥$, it contains a bottle of red wine discounted at the supermarket, $19.9 ¥$ to buy two red wine glasses, $9.9 ¥$ with a small white mat. The most difficult thing is that pouring wine can't always produce beautiful effects, either too fast or sprinkling, but they later processed slowly through the app on the mobile network terminal device to achieve the desired effect. Unfortunately, during the procedure they forgotten to whiten the chin of the male student who play in the ad.

\subsection{New Teaching Mode is Popular Among Students}

In the class that implements the new teaching model for feedback evaluation, most students believe that the mode of teaching using mobile network terminals is very novel, the teaching content is richer, the participation of students is very high, and all group work is completed on time, let them Can learn knowledge more and more consciously, and even take the initiative to expand learning. They believe that the results of each class are very fulfilling and hope to learn more useful knowledge. Taking student $A$ as an example, the use of mobile terminal equipment in learning can be clearly reflected on the app, which is convenient for teachers to flexibly adjust the teaching design and enhance the teaching effect.: 


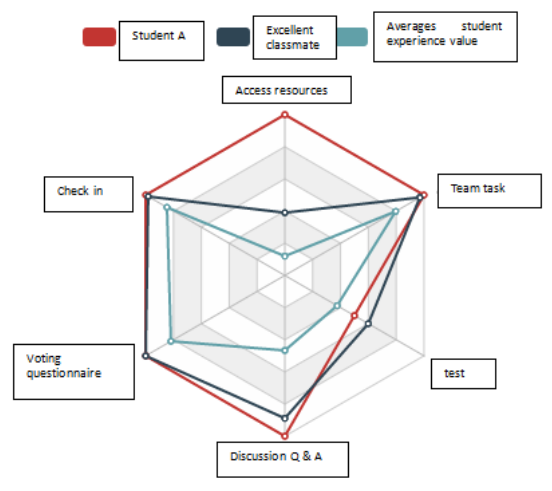

Fig 1. student A compare with excellent classmate and average student

The actual case shows that the use of mobile network teaching has greatly improved the enthusiasm and participation of students, and broadened the depth and breadth of the teaching content, so that students can talk more about the topic, rather than simple and mechanical reciting of the texts. the teaching in the mobile network environment makes the students become the main body of the curriculum teaching, and also makes the teaching of the curriculum more flexible. The wisdom and processing methods generated by the students in the participation can often surprise the teachers. promote teacher-student relationship into benign interaction and communication, greatly improving the teaching effect.

\section{Conclusion}

Under the mobile network environment, the exploration and construction of communication English in business teaching mode can re-position the main body of classroom teaching, improve the ability of teachers and students to use mobile networks, give play to the advantages of mobile network teaching, and ensure the effectiveness and quality of English teaching in business communication.

\section{References}

[1]. Xue Qifeng. Discussion on the Teaching Mode of College English Listening and Speaking in Multimedia Network Environment[J]. Curriculum Education Research, 2018(9): 116-page 117.

[2]. Zhang Shandi. Research on College English Translation Teaching Model under the Network Environment [J]. Comparative Study of Cultural Innovation, 2018(12): Page 78-page 80.

[3]. Hai Xiaoli. College English Teaching Model Based on Network Cloud Platform and Bisection Classroom[J]. Culture and Education Materials, 2018(11): Page 65-page 66. 